\title{
Ready for Labor and Defense (GTO) Complex as the System of Physical Readiness of Population Control
}

\author{
Zyurin E.A. \\ Federal Scientific Center of Physical Culture and Sport \\ Moscow, Russia
}

\author{
Petruk E.N. \\ Federal Scientific Center of Physical Culture and Sport \\ Moscow, Russia
}

\author{
Bobkova E. N. \\ Smolensk State Academy of Physical Culture, Sport and Tourism \\ Smolensk, Russia
}

\begin{abstract}
The article considers the question of control in the system of adults' physical education. Nowadays in the system of adults' physical education only the final control is used based on the results of RLD (GTO) complex tests fulfillment for gold, silver and bronze badges. At the same time, different physical loads influence on an organism of those, who go in for physical culture, taking into account gender and age, professional activity peculiarities is not studied. Entrance and current control over physical activity and adults' physical readiness level realization revealed considerable contradictions between the level of readiness and testing effectiveness according to RLD (GTO) complex. The received results prove the necessity to create unified programs of population physical activity, taking into account morphological-functional state, physical readiness, gender and age, professional activity.
\end{abstract}

Keywords-adults; RLD (GTO) complex; physical readiness; physical development; programs of training; motivation.

\section{INTRODUCTION}

Modern society development places great demands on the level of physical development and physical readiness, as the basis of working capacity and a person's defensive powers of an organism formation [4].

\section{LITERATURE REVIEW}

The effectiveness of adults' physical upbringing system depends on the state of health and the main physical qualities development of those, who train [3]. Objective information about physical readiness level of population, especially at the stage of professional skills formation, has a great practical value [2].

Physical activity of adults is mainly conditioned by the character of motivation and the degree of the places availability, where people master physical exercises [1]. Physical readiness control and estimation among population give an opportunity to form rationally and correct the system of adults' physical upbringing [8, 9]. RLD (GTO) complex is a forming element of physical upbringing system among adults, directed toward physical development and physical readiness level increase among different groups of population and can be an adequate system of physical training control [6].

To define the effectiveness of control in the system of physical training among adults on the basis of RLD (GTO) complex use.

\section{RESEARCH METHODOLOGY}

During the pedagogical experiment the group is formed consisting of 50 men and 50 women at the age of 40-49, who live in Moscow and Moscow region, who went in for physical exercises systematically according to the offered program of independent training for RLD (GTO) testing. During the experiment pedagogical observation was realized, morphological-functional indices were measured (heart rate, blood pressure, carpal strength, lung capacity (LC) at expiratory flow), physical readiness testing according to tests, taking into account the stages, which are included into RLD complex.

\section{IV.RESULTS}

Physical culture and mass sport development in the Russian Federation is realized in terms of the Russian Federation state program "Physical culture and sport development" $[10,11]$. RLD realization in this country becomes one of the main instruments of events organization according to further state policy development in the sphere of physical culture and mass sport, an effective system of physical upbringing creation, directed toward human potential development and health improvement among population [6]. One of these events realization instruments is control, the aim of which is connections determination between the factors of influence and morphological-functional state changes and physical readiness of those, who train. Control includes observation, analysis, estimation and physical upbringing system correction and the degrees of physical development and physical readiness of adults' optimization.

The participants of the experiment, who planned to fulfill RLD (GTO) tests, were offered the program of independent training, the obligatory part of which was entrance, current and final control. During the experiment 
respondents independently stated forms, methods, means of lessons and the load on the electronic platform "Physical readiness and population activity rating in RLD (GTO) realization", which helped to define activity level of the respondents in realization of the training program for testing and helped to reveal the dynamics of physical readiness level.

During the experiment we studied morpho-functional state and physical readiness of the respondents [5]. The level of physical readiness determination was realized on the basis of RLD complex tests according to 8 tests of "State demands placed on the level of physical readiness of population" [7], in accordance with the age group. It was stated that there were valid improvements $(\mathrm{P}<0,05)$ in significance level both among men and women at the end of the experiment. The greatest results increase was among men in the following tests: 60 meters running, $3 \mathrm{~km}$ running, head lean from standing position at a gymnastic bench, sports projectile throwing and shooting. In dip up and 50 meters swimming there were no valid differences in the received results $(\mathrm{P}>0,05)$. Among women validly significant improvements were in all kinds of tests. It was revealed experimentally how useful physical training is for morphological-functional state of the experiment participants and the effectiveness during RLD complex tests fulfillment (table 1).

\section{TABLE I. PHYSICAL READINESS OF THE TEST PARTICIPANTS BEFORE AND AFTER THE EXPERIMENT}

\begin{tabular}{|c|c|c|c|c|c|c|c|c|}
\hline \multirow[b]{2}{*}{ Participants of testing } & \multicolumn{8}{|c|}{ Kinds of tests } \\
\hline & 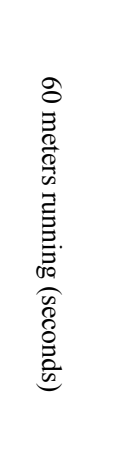 & 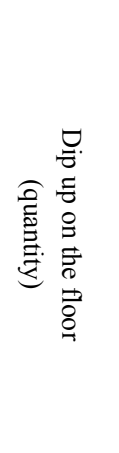 & 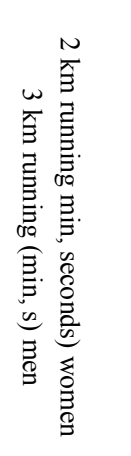 & 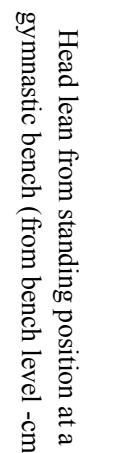 & 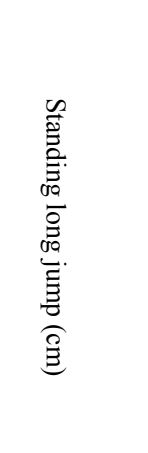 & 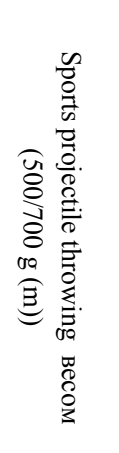 & 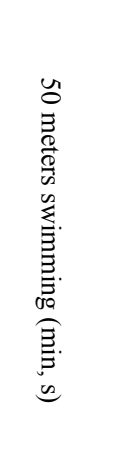 & 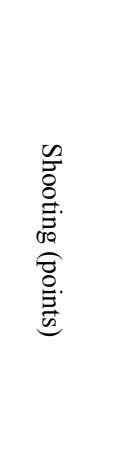 \\
\hline \multicolumn{9}{|l|}{ Men n 50 } \\
\hline before the experiment & $10,6 \pm 1,6$ & $26,7 \pm 5,7$ & $14.21 \pm 1,4$ & $6,74 \pm 3,5$ & $218 \pm 16$ & $30,7 \pm 3,3$ & $1.16 \pm 0,3$ & $26 \pm 8,2$ \\
\hline after the experiment & $9,9 \pm 1,6$ & $34,6 \pm 8,9$ & $13.39 \pm 1,2$ & $11,1 \pm 4,0$ & $228 \pm 14,9$ & $35,5 \pm 3,4$ & $0,59 \pm 0,3$ & $33 \pm 10,5$ \\
\hline $\mathrm{t}$ criterion & $\mathrm{P}<0,05$ & $\mathrm{P}>0,05$ & $\mathrm{P}<0,05$ & $\mathrm{P}<0,05$ & $\mathrm{P}<0,05$ & $\mathrm{P}<0,05$ & $\mathrm{P}>0,05$ & $\mathrm{P}<0,05$ \\
\hline \multicolumn{9}{|l|}{ women n 50} \\
\hline before the experiment & $11,8 \pm 1,6$ & $10,8 \pm 4,4$ & $13.27 \pm 1,3$ & $8,58 \pm 4,1$ & $147,9 \pm 29$ & $14,4 \pm 4,3$ & $2.00 \pm 0,2$ & $20,8 \pm 4,5$ \\
\hline after the experiment & $11,5 \pm 1,6$ & $14,6 \pm 6,2$ & $12.48 \pm 1,5$ & $12,3 \pm 4,6$ & $159,8 \pm 32,8$ & $18,7 \pm 6,7$ & $1.35 \pm 0,3$ & $26 \pm 5,4$ \\
\hline $\mathrm{t}$ criterion & $\mathrm{P}<0,05$ & $\mathrm{P}<0,05$ & $\mathrm{P}<0,05$ & $\mathrm{P}<0,05$ & $\mathrm{P}<0,05$ & $\mathrm{P}<0,05$ & $\mathrm{P}<0,05$ & $\mathrm{P}<0,05$ \\
\hline
\end{tabular}

The results of respondents' physical readiness and morphological-functional state prove that the center of testing is attended by physically developed and functionally trained citizen of male and female gender. Regardless of positive dynamics during the experiment statistical data (results of statistical report 2-RLD, 2018) showed that 52,5\% of population of the Russian Federation, who started to fulfill RLD (GTO) complex, didn't go through the tests.

Moreover, control realization in the system of adults' physical upbringing in the Russian Federation nowadays revealed several contradictions:

- there is no integral scientifically substantiated conception of great research works organization in the sphere of adults' physical development and physical readiness control and monitoring;

-during urgent problems solution concerning RLD complex realization modern mechanisms of organization interaction between regional and federal structures in control organization are not used in the system of physical upbringing and population physical development monitoring;

- there is no optimal model of RLD complex scientificmethodical support, which would provide control and monitoring organization of big population samplings.

The presented situation proves the necessity to standardize and unify different technologies of adults' physical training with the necessity of its practical realization at regional and federal levels.

\section{CONCLUSION}

The received results prove that the effectiveness of adults' physical training control on the basis of "Ready for labour and defense" complex use depends on systematic character of information getting concerning the level of motor activity and physical training of population.

Unified programs of population physical activity creation and realization, including RLD complex tests fulfillment, in accordance with physical readiness level, 
gender and age, professional activity, which includes the elements of pedagogical control (entrance, current and final) will provide adults involvement into physical culture and sports activity.

\section{References}

[1] Andreeva E.V. Motivational theories analysis in the sphere of health improving physical culture and recreation. Theory and methodology of physical upbringing and sport. 2004,2, pp. 81-82.

[2] Varenik O.N., Shlepakov L.N. Priority directions of activity improvement in the system of sport for all at regional level. Science and sport: modern tendencies. 2014, vol. 2, 1, pp. 99-104.

[3] Zyurin E.A., Bobkova E.N., V.N. Morozov, S.A.Polievskiy Physical activity of population as the factor of All-Russian Physical culture and Sport Complex RLD in the Russian Federation in 2016-2017. Theory and practice of physical culture. 2018, 11, pp. 41-43.1.

[4] Isaev A.P., Gattarov R.U., Korolkov V.V. Role of physical culture and sport in the question of society health improvement and the national safety of the country. South-Ural State University bulletin. 2010, 24(200), pp. 10-14.

[5] 5. Nikolaev A.A. Motor activity and health of a modern person: Manual for teachers and students of physical culture higher educational establishments. Smolensk: Smolensk State Institute of Physical Culture. 2005, pp. 52-61.

[6] Resolution of government of the Russian Federation on June, 11, 2014 № 540 "On the thesis adoption about All-Russian physical culture and sport complex "Ready for labor and defense" (with changes and additions). URL: http://base.garant.ru/70675222/.

[7] The order of the Ministry of Sport of the Russian Federation on 12.02.2019 № 90 "On state demands adoption of All-Russian physical culture and sport complex "Ready for labor and defense". URL: https://minjust.consultant.ru/documents/42248.

[8] Savenkova E.A., Simkachev S.A., Tikhomirov M.V. Expert methodology of estimation criteria choice in physical culture and sport development in the subjects of the Russian Federation. Sports science bulletin. 2010, 4, pp. 37-41.

[9] Chipysheva L.N. The notions "control" and "estimation" in pedagogical science. Pedagogical sciences. 2006, 6(21), pp. 98101.

[10] Erkabulan Islyamov, Zinaida M. Kuznetsova. The most popular national sports and games of the Republic of Kazakhstan. The Russian journal of Physical Education and Sport. 2019, 14(1), pp. 114-121. DOI: 10.14526/2070-4798-2019-1-1-132-140.

[11] Resolution of government of the Russian Federation on January, 21 2015 № 30 (edition 18.06.2019) “On federal target program "Physical culture and sport development in the Russian Federation within the period 2016-2020". URL: https://base.garant.ru/70852372/. 